\title{
Psychological Considerations to Use Alternative Therapies
}

\author{
Shah Murad ${ }^{1 *}$, Fasiha Fatima ${ }^{2}$, A Qudoos ${ }^{3}$, Seema $^{4}$, Abdul Ghaffar ${ }^{5}$ and Jamila Shah ${ }^{6}$ \\ ${ }^{1}$ Professor of Pharmacology, IMDC, Pakistan
}

${ }^{2}$ Assistant Professor of Biochemistry at KIMS, Pakistan

${ }^{3}$ Associate Prof of Pharmacology at HBSMC Islamabad, Pakistan

${ }^{4}$ Gynecologist at NMC Karachi, Pakistan

${ }^{5}$ CWO at IMDC and DANTH, Pakistan

${ }^{6}$ Psychologist at BU Karachi, Pakistan

*Corresponding author: Shah Murad, Professor of Pharmacology, IMDC, Pakistan

\begin{abstract}
Obesity is physical as well as psychological problem in human population. Dyslipidemia is alteration of normal levels of good and bad cholesterol in human body. It can cause heart diseases like hypertension, cardiac arrhythmias, and heart attack. Niacin, Statins, BABR and fibrates are used to normalize dyslipidemia. Medicinal herbs have been researched and found effective to normalize plasma lipids with different characteristics.

Object of research: Aim of this research was to compare individual and combined effects of Ispaghola and Anjeer in primary as well as secondary hyperlipidemia.

Design: It was single blind placebo-controlled research work, conducted from March 2018 to September 2018 at General Hospital, Lahore, Pakistan.

Sample size: One hundred male and female hyperlipidemic patients were selected for research, age range from 20 to 65 years. Inclusion criteria were primary, secondary hyperlipidemic patients. Written and explained consent was taken from all participants and approved by research ethics committee of the hospital. Patients were divided in four equal groups, comprising 25 patients in each group.

Method: Their baseline systolic/diastolic blood pressure and lipid profile was estimated and kept in individual's folder. Group-I was on Ispaghula 10 grams, group-II was on 10 grams Anjeer, and group-III was advised to take 10 grams Ispaghula, and 10 grams Anjeer in combination for 3 months. Group-IV was on placebo therapy.

Results: After 3 months when results were compiled and analyzed statistically, it was observed that Ispaghula decreased LDL-c significantly with p-value $<0.05$, Anjeer decreased LDL-c significantly with $\mathrm{p}$-value $<0.01$. When both herbs were combinely given, they reduced systolic BP with p-value $<0.01, \mathrm{LDL}^{-\mathrm{c}}$ reduced highly significantly with p-value $<0.001$, and $\mathrm{HDL}^{-\mathrm{c}}$ increased significantly with p-value $<0.05$.
\end{abstract}

Conclusion: It was concluded from the study that Ispaghula and Anjeer have $\mathrm{LDL}^{-\mathrm{c}}$ lowering potential if given separately. When used in combination they reduce systolic BP, $\mathrm{LDL}^{-\mathrm{c}}$, and increase $\mathrm{HDL}^{-\mathrm{c}}$.

\section{Introduction}

Modern lifestyle in developed and developing countries has produced different physical and psychological illnesses including obesity, aging, dyslipidemia, coronary artery disease, depression, lung, uterus, cervical, oral, and breast cancer. The problem is that conventional medicine is unable to identify the actual causes and

thus can only treat or "cover" the respective symptoms. Recent heart illnesses are due to sedentary life style, utilization of bakery foods, alcohol use, cigarette smoking and use of unprescribed medications [1]. Due to unwanted effects of allopathy related hypolipidemic drugs, herbal medicines are individually used or combined with 
herbs to decrease hyperlipidemia, CAD incidence leading to morbidity or mortality [2]. Secondary and primary hyperlipidemia cause LDL-oxidation, leading to formation of atherosclerotic plaques which get deposited at interior wall of coronary vessels, making it narrow and causing, hypertension, CCF, cardiac arrhythmias, and cardiac arrest [3-6]. To decrease incidences of advanced heart diseases, it is necessary to leave sedentary life, over consumption of alcohol, cigarette smoking, to reduce body weight [7].

Allopathic drugs used in hyperlipidemia have unwanted effects on human body, so herbs can be safe to use in prevention and treatment of primary as well as secondary hyperlipidemia [8]. Psyllium hydrophilic muciloid or Ispaghola inhibit enterohepatic circulation of bile and excrete it out through feces. This causes liver cells to synthesize bile instead of cholesterol synthesis [9]. Using psyllium husk will ultimately minimize the storage of triglycerides and reduce overall burden of triglycerides. Adding a teaspoon of psyllium husk in food is often recommended. However, adding more water is also recommend along with this fiber, as it retains significant volume of water and swell. Along with lowering triglycerides naturally, it also helps in constipation, lower cholesterol, act as a safe laxative, and can be used to lose weight [10]. In Greek mythology, the fig figures prominently as a gift of Demeter to Dionysus and as having received the blessing and sanctity of the Greek Gods [11]. Figs are a great source of potassium, which helps to regulate blood pressure and other important bodily functions. Omega 3 and Omega 6 they contain help to maintain blood pressure and coronary heart attacks [12]. Leaves of figs help in lowering the levels of triglycerides, which are major form of fat produced and stored in the body. Increased triglycerides are often associated with obesity and heart disease [13]. It's well known that fig leaves can be consumed for anti-diabetic properties, they lower the amount of insulin required by diabetics [14].

\section{Patients and Methods}

\section{Desin of research}

It was single blind placebo-controlled research work, conducted from March 2018 to September 2018 at General Hospital, Lahore, Pakistan

\section{Selection of patients}

One hundred male and female hyperlipidemic patients were selected for research, age range from 20 to 65 years. Inclusion criteria: Inclusion criteria were primary, secondary hyperlipidemic patients. Exclusion criteria was patients suffering from any chronic illness like CCF, cardiac arrhythmias, thyroid disease, peptic ulcer, Alzheimer's disease, major depression, and renal or hepatic impairment.

\section{Consent}

Written and explained consent was taken from all participants and approved by research ethics committee of the hospital. Patients were divided in four equal groups, comprising 25 patients in each group. Method-Their baseline determination of LDL-cholesterol and HDL-cholesterol was made at Biochemistry laboratory and was kept in specially formatted Performa. Group-I was advised to take dried Figs 10 grams daily in three equally divided doses. Group-II was advised to take 10 grams of Psyllium husk daily in three divided doses before each meal for three months (Table 1). Group-III was advised to take 10 grams Figs and 10 grams Psyllium husk in three divided doses daily for three months. Group-IV was advised to take one capsule (containing grinded wheat) with each mealtime, thrice daily for the period of three months. They were advised to come for follow up monthly. Their LDL-cholesterol and HDL-cholesterol, blood pressure was measured/determined monthly.

Table 1: Showing Pre- And Post-Treatment Mean Values, \pm Sem, Changes In Results And Biostatistical Significance.

\begin{tabular}{|c|c|c|c|c|c|c|}
\hline Group of patients & $\begin{array}{c}\text { Evaluated } \\
\text { parameters }\end{array}$ & $\begin{array}{l}\text { Pre-treatment } \\
\text { values }\end{array}$ & $\begin{array}{c}\text { Post-treatment } \\
\text { values }\end{array}$ & $\begin{array}{c}\text { Change in pre and } \\
\text { post-treatment values }\end{array}$ & $\begin{array}{l}\text { Change in } \\
\text { percentage }\end{array}$ & p-value \\
\hline $\begin{array}{l}\text { Ispaghula } \\
\mathrm{n}=23\end{array}$ & $\begin{array}{c}\text { SBP } \\
\text { DBP } \\
\text { LDL }^{-c} \\
\text { HDL }^{-c}\end{array}$ & $\begin{array}{c}130.11 \pm 2.01 \\
89.45 \pm 1.98 \\
179.04 \pm 2.18 \\
38.43 \pm 1.65\end{array}$ & $\begin{array}{c}125.89 \pm 2.00 \\
87.91 \pm 2.90 \\
169.98 \pm 2.76 \\
41.87 \pm 1.95\end{array}$ & $\begin{array}{l}4.22 \\
1.54 \\
9.06 \\
3.44\end{array}$ & $\begin{array}{l}3.24 \\
1.72 \\
5.06 \\
8.95\end{array}$ & $\begin{array}{l}>0.05 \\
>0.05 \\
<0.05 \\
>0.05\end{array}$ \\
\hline $\begin{array}{l}\text { Anjeer } \\
n=25\end{array}$ & $\begin{array}{l}\text { SBP } \\
\text { DBP } \\
\text { LDL }^{-c} \\
\text { HDL }^{-c}\end{array}$ & $\begin{array}{c}133.55 \pm 1.75 \\
91.65 \pm 1.54 \\
175.88 \pm 2.67 \\
33.86 \pm 1.74\end{array}$ & $\begin{array}{c}130.06 \pm 1.09 \\
85.96 \pm 2.02 \\
159.20 \pm 2.66 \\
39.01 \pm 2.64\end{array}$ & $\begin{array}{c}3.49 \\
5.69 \\
16.68 \\
5.15\end{array}$ & $\begin{array}{c}2.61 \\
6.2 \\
9.48 \\
15.2\end{array}$ & $\begin{array}{l}>0.05 \\
>0.05 \\
<0.01 \\
>0.05\end{array}$ \\
\hline $\begin{array}{c}\text { Ispaghula }+ \text { Anjeer } \\
n=25\end{array}$ & $\begin{array}{c}\text { SBP } \\
\text { DBP } \\
\text { LDL }^{-c} \\
\mathrm{HDL}^{-c}\end{array}$ & $\begin{array}{c}134.76 \pm 1.88 \\
90.49 \pm 2.63 \\
178.76 \pm 3.12 \\
39.61 \pm 2.61\end{array}$ & $\begin{array}{c}121.88 \pm 2.76 \\
85.02 \pm 3.96 \\
160.99 \pm 3.86 \\
48.69 \pm 3.63\end{array}$ & $\begin{array}{c}12.88 \\
5.47 \\
17.77 \\
9.08\end{array}$ & $\begin{array}{c}9.55 \\
6.04 \\
9.94 \\
22.92\end{array}$ & $\begin{array}{c}<0.01 \\
>0.05 \\
<0.001 \\
<0.05\end{array}$ \\
\hline $\begin{array}{c}\text { Placebo } \\
n=24\end{array}$ & $\begin{array}{c}\text { SBP } \\
\text { DBP } \\
\text { LDL }^{-c} \\
\text { HDL }^{-c}\end{array}$ & $\begin{array}{c}120.05 \pm 1.87 \\
75.85 \pm 2.91 \\
141.05 \pm 1.97 \\
42.56 \pm 2.06\end{array}$ & $\begin{array}{c}119.77 \pm 2.91 \\
75.01 \pm 2.77 \\
140.25 \pm 2.22 \\
42.59 \pm 1.64\end{array}$ & $\begin{array}{c}0.28 \\
0.84 \\
0.8 \\
0.03\end{array}$ & $\begin{array}{c}0.23 \\
1.1 \\
0.56 \\
0.07\end{array}$ & $\begin{array}{l}>0.05 \\
>0.05 \\
>0.05 \\
>0.05\end{array}$ \\
\hline
\end{tabular}




\section{Biostatistical analysis}

After three months all parameters were evaluated like their blood pressure and lipid profile. Results were compiled and statistically analyzed by using SPSS version 5.0 2014. Mean values of the tested parameters were expressed with \pm SEM and paired ' $\mathrm{t}$ ' test was applied to determine significant changes in mean values before and after treatment. P-value $>0.05$ was considered as nonsignificant change, $p$-value $<0.01$ was considered as significant and $p$-value $<0.001$ was considered as highly significant change in tested parameters.

\section{Results}

When results were compiled and statistically analyzed, it was observed that Ispaghula reduced SBP of 23 patients from $130.11 \mathrm{~mm}$ of hg to $125.89 \mathrm{~mm}$ of $\mathrm{hg}$, and 89.45 to $87.91 \mathrm{~mm}$ of hg in systolic and diastolic BP respectively. Both are non significant results. $9.06 \mathrm{mg} / \mathrm{dl}$ decrease in $\mathrm{LDL}^{-\mathrm{c}}$ was observed which is significant change. $\mathrm{HDL}^{-\mathrm{c}}$ was increased from $38.43 \pm 1.65$ to $41.87 \pm 1.95 \mathrm{mg} / \mathrm{dl}$ which is non-significant change in the parameter. Anjeer decreased 133.55 to $130.06 \mathrm{~mm}$ of hg and 91.65 to $85.96 \mathrm{~mm}$ of hg in systolic and diastolic BP respectively, and change in both parameters are non-significant. This fruit reduced LDL ${ }^{-c}$ from 175.88 to $159.20 \mathrm{mg} /$ $\mathrm{dl}$ in 25 hyperlipidemic patients which is significant change in the parameter. $\mathrm{HDL}^{-\mathrm{c}}$ increased from 33.86 to $39.01 \mathrm{mg} / \mathrm{dl}$ which is non-significant change. When both agents were used combinely SBP, and DBP were decreased from 134.76 to 121.88 and 90.49 to $85.02 \mathrm{~mm}$ of hg in 25 patients. Change in systolic BP is significant but in diastolic BP it is non-significant change. $\mathrm{LDL}^{-\mathrm{c}}$ in this group was reduced from 178.76 to $160.99 \mathrm{mg} / \mathrm{dl}$ which is highly significant change in the parameter. $\mathrm{HDL}^{-\mathrm{c}}$ was increased from 39.61 to $48.69 \mathrm{mg} / \mathrm{dl}$ which is significant change. In placebo group changes in all parameters are non-significant.

\section{Key}

All parameters and change before and after treatment in parameters are measured in $\mathrm{mg} / \mathrm{dl}$, and their mean values are written with \pm SEM. P-value $<0.01=$ significant, $\mathrm{p}$-value $>0.05=$ non-significant changes in lipid profile. $\mathrm{HDL}^{-\mathrm{c}}$ and $\mathrm{LDL}^{-\mathrm{c}}$ values are measured in milligrams per milliliter. SBP stands for systolic blood pressure, DBP stands for diastolic blood pressure and were measured in millimeter of mercury (HG). $\mathrm{n}=$ sample size.

\section{Discussion}

Mental health means different things to different people. You may think of control, happiness, contentment, order-but good mental health is usually a sign of a positive way of life. Mental ill health is the opposite of this-it causes problems and creates barriers to being happy. Your frame of mind may vary between the two as mental health can change. It can be affected by external influences, and one of these is drugs. Beyond the fecal properties, psyllium appears to be able to reduce total cholesterol and LDL cholesterol in persons with high cholesterol and there is a slight reduction of HDL as well. This is common to all dietary fibers and is not unique to psyllium. Traditionally, figs have been used to treat constipation, bronchitis, high cholesterol, eczema, psoriasis (chronic skin disease), vitiligo (white skin patches), and diabetes (high blood sugar). Topically, its latex has been used to remove warts and treat skin tumors. At this time, there are no high quality human trials supporting the effectiveness of fig for any indication. However, the antioxidant activity and cytotoxicity against various cancer cell lines reported in fig are potentially promising in its future therapeutic uses. Flavonoids, fluranocoumarins, organic acids found in fresh or dried anjeer (figs) have hypolipidemic features [15]. In our observation Ispaghula reduced $\mathrm{LDL}^{-\mathrm{c}}$ in 23 patients which is significant when analyzed statistically.

Ispaghula's effects in other parameters are very mild and nonsignificant. These results match with results of study conducted by Jolatha [16], who did observe almost same changes in LDL ${ }^{-c}$ when 30 grams of ispaghula was used for one month in 30 hyperlipidemic patients. Falker T [17] explained MOA of Ispaghula as hypolipidemic agent that husk of these seeds inhibit enterohepatic circulation of bile causing synthesis of bile instead of cholesterol by hepatocytes. Wolyn P [18] explained that $\mathrm{HDL}^{-\mathrm{c}}$ must be increased when too much psyllium husk may be used in remarkable time period, but sample size also counts, they further explained. Jeajath C [19] stated that apoproteins formation in liver cells is most important step induced by psyllium husk as hypolipidemic agent. Anjeer when used alone in 25 hyperlipidemic patients in our observation are effective to reduce $\mathrm{LDL}^{-\mathrm{c}}$ only, as other parameters proved no significant changes. It was also proved by study conducted by Restham $\mathrm{T}$ [20].

They proved $13 \%$ decrease in $\mathrm{LDL}^{-\mathrm{c}}$ in 53 hyperlipidemic and hypertensive patients when they used 10 grams anjeer for four months. Subh H [21] wrote that environmental factors affect study results when sample is only taken from human population. Close observation and frequent follow up visits are needed and necessary steps in human involved research work. Astolth ER [22] advised their patients for strict half an hour physical exercise and banned them to take any processed and diary foods during their drug trial. They also got same results of anjeer fruit in hyperlipidemic and hypertensive patients. Ethere C [23] used fruit extract of anjeer in albino rats and proved that $\mathrm{HDL}^{-\mathrm{c}}$ may be affected significantly. These results explain close observatory environment for avoiding any false data/results during any sensitive research work. In our research it was proved that combination of anjeer and psyllium husk affect on systolic BP, $\mathrm{LDL}^{-\mathrm{c}}$ and $\mathrm{HDL}^{-\mathrm{c}}$, but diastolic BP is not affected significantly. Thyswe JE [24] proved biostatistically significant effects of psyllium seeds and anjeer on $\mathrm{LDL}^{-c}, \mathrm{HDL}^{-c}, \mathrm{TG}$, TC, VLDL in diet-induced hyperlipidemic mice. Again it is proved and strongly recommended that controlled environment is first necessary step to get true results from research work. Jouhall $\mathrm{C}$ [25] mentioned that combination of fruit extracts and fiber content 
diet like ispaghula surely normalize lipid profile, blood pressure, and hyperglycemia due to antioxidant effects of this combination. Dundha B, Melhrr Y, Erwih C, Juthr V, Rehav C, et al. [26-32] mentioned that leaves, bark, tender shoots, fruits, seeds and latex of figs contain various phytochemicals that are antioxidants and can be used as antidiabtes, hypolipidemic and hypotensive agents.

\section{References}

1. Bhughu T, Welkty S, Swath RT (2014) Beyond the history: Hyperlipidemia and Antioxidants. Cl Jou Nutr Med 6(7): 45-47.

2. Mukkr TY, Jethusa MM, Mattak GG, Fuller CV (2014) Preventable factors for CAD. Jou Cl Med 8(3): 22-26.

3. Sertr ER, Rusat VB (2012) Use of Herbs in Variuous Ethnic Groups. Ethan Bot J 15(7): 77-83.

4. Bolwa J, Johnson SC, TY Mokrann (2013) Prevention is better than tretment in heart diseases. JCHD 4(4): 33-39.

5. Selvth Y, Laguerre M, Lecomte J, Villeneuve P (2012) Medications used in oxidative stress. Ir J Med Sc 6(2): 61-69.

6. Ruthy TG (2012) Herbs in general considerations. HHJ 6(3): 88-90.

7. Milionis HJ, Elisaf MS (2010) Do statins beneficially or adversely affect glucose homeostasis? Curr Vasc Pharmacol 8(5): 612-631.

8. Selva R, Fudaat T (2013) Complications of Hyperlipidemia. Jou Ir Med 4(1): 1-8.

9. Sughth P, Desortin J, Ulharv R (2013) New approaches to foods and heart diseases. J Nutr pp: 501-504.

10. Erwah T, Tyus T, Malker T (2012) Enterohepatic circulation and bile. GIT Jou 6(4): 222-228.

11. Mulwat R, Jahily C, Pitwat F (2014) Bile acid binding resins and healthy heart. Vas Jou Is 4(2): 200-204.

12. Yulr B, Therw E (2012) Clean your gastrointestinal tract and remain healthy. Health \& Nutr 6(4): 222-225.

13. Mallku V, Peraze C, T Mughwann (2012) Hyperlipidemia, Psyllium husk and Heart. New Jou Vas Med 3(6): 344-347.

14. Parkash A (2013) Ficus carica and heart diseases. Eth Bot 4(5): 77-90.

15. Thermaw T, Fedarr K, Kiltu M, Futhat G (2014) Phytochemistry of ficus carica. Phyt J 12(5): 555-557.

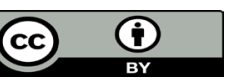

This work is licensed under Creative

Commons Attribution 4.0 License

To Submit Your Article Click Here:

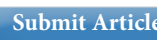

16. Jolatha J, Kilty T, Juthy Y, Marstein M, Ythfaw C (2015) 30 grams psyllium for one month for cure of atherogenesis. Vas J Med 4(7): 333-337.

17. Falkerr T, Rusth M, Helmoy T, Welkr J, Urth J (2012) Mode of action of Ispaghola. Eth Jou Bot 5(5): 122-127.

18. Wolyn P, Nesthy Y, Thupase T, Thymosrr F, Molleri H (2015) Effects of psyllium on lipid profile. Lipids J 6(7): 222-226.

19. Subh H, Serou T, Kulhar O, Ildu F (2013) Apoproteins and blood lipids. Cardio J Ir 6(7): 612-615.

20. Restham T, Buldow E, Molakt V (2015) Interaction of bad cholesterol with ficus carica. Ann SMC 6(5): 100-105.

21. Jufthas Y, Lamaj V, Helkaar C, Huiow B (2016) Research protocols and methodologies. NJDDT 2(6): 12-17.

22. Astolth ER, Yuthmas DD, Fituhar VR (2012) How to deal with lipids research? JCNM 6(1): 19-23.

23. Ethere C, Yethma N, Melojaw V, Juhlakhand G (2011) Use of Ficus carica in albino rats. Egy J Cl H Sc 7(6): 456-459.

24. Thyswe JE, Thymolov YR, Teetehar RR (2016) Use of herbs for normalizing blood lipids. Cl Res J 6(8): 88-90.

25. Jouhall C, Welker T, Ethere C, Jugath Y (2014) Treatment of diabetes, hypertension, and hyperlipidemia by herbs. Herb Med J 6(6): 578-581.

26. Dundha B, Kilerr T, Mithwth G, Mujhkt P (2014) Do not use plants as medicine? JNRR 9(13): 50-58.

27. Melhrr Y, Rusth U, Mrsik T, Yulwr T, Misku (2016) Treatment of metabolic syndrome. Cl Jou Ther Pl 9(10): 88-90.

28. Erwih C, Rolka T, Moju Y, Uswva T, Mellay G (2014) Role of other things in therapeutics discipline. Res Jou Plants 77(8): 367-369.

29. Juthr V, Molka R, kilwar T, Johth Y (2016) How to use asthetic medications. Res Che Pl 8(11): 456-459.

30. Rehav C, Jelghat G, Ulvr P, Melku U, Yulwa S (2012) Role of fruits in diseases processes. Jou Cl Nut Res 8(9): 334-339.

31. Rispr R, Tolht F, Miskn O, Kith J (2015) The Plants: Considerations in Medicine. RVCPJ 11(9): 99-104.

32. Rolaku J, Dolhara J, Jiswth P, Malkui T, Musthr K (2014) Antioxident properteies of anjeer. JPCCR 23(7): 55-59.

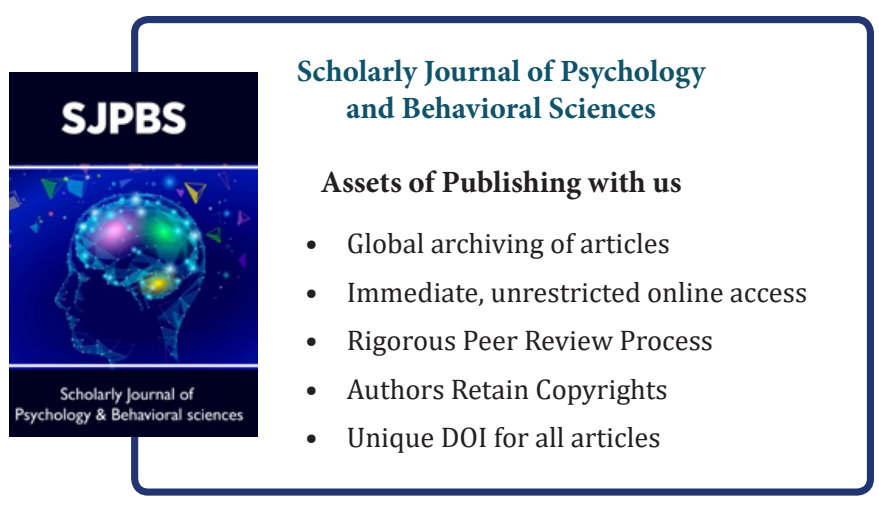

